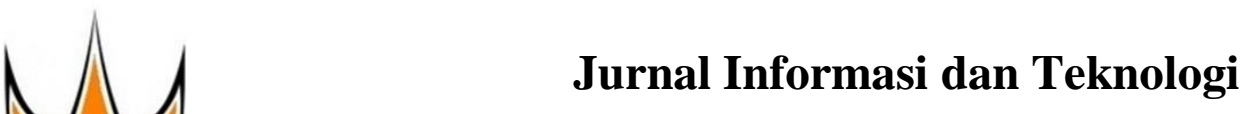

http://www.jidt.org

$2021 \quad$ Vol. $3 \quad$ No. $4 \quad$ Hal: $215-220$

e-ISSN: 2714-9730

\title{
Sistem Keputusan Dengan Metode Multi Attribute Utility Theory Dalam Penilaian Kinerja Pegawai
}

\author{
Fuad El Khair $^{1 凶}$, Sarjon Defit ${ }^{2}$, Yuhandri Yunus ${ }^{3}$ \\ ${ }^{1,2,3}$ Universitas Putra Indonesia YPTK Padang \\ fuade1khair96@gmai1.com
}

\begin{abstract}
In an agency, it takes an employee who is able to carry out the work in accordance with the objectives in achieving a target becomes an assessment by the leaders. Not only attendance, but also leadership, commitment, cooperation, discipline, service orientation, integrity and ability to perform the task given also need to be used as an indicators. The purposes aim to motivate employees to be passionate in doing every activity and to have a positive influence on their work in facing challenges of globalization. Decision Support System is a need. It is called a Multi Attribute Utility Theory method is a quantitative comparison method that usually combines measurements of different risk costs and benefits. The data processed for employee performance assessment in this study as many as 20 samples sourced from the Population and Civil Registration Office of Pesisir Selatan Regency. This based on several specified criteria and weights. There are 6 data that are used in it. Such as service orientation, integrity, commitment, discipline, cooperation and employee performance goals. The result is able to support employee decisions using predetermined criteria. So that highest value is in the 6th alternative with a value of 0.7918 and the lowest value on the 16th alternative with a value of 0.0435 . Later it will be a consideration for Population and Civil Registry Office of South Coast Regency to assess its employees in certain period. Employee performance assessment is proven to be able to help the South Coast Population and Civil Registration Office.
\end{abstract}

Keywords: Decision Systems, Multi Attribute Utility Theory, Assessment, Performance, Employees.

\begin{abstract}
Abstrak
Pada suatu instansi, dibutuhkan pegawai yang mampu melaksanakan pekerjaan sesuai dengan tujuan dalam mencapai suatu target yang menjadi penilaian oleh pimpinan terhadap pegawai. Jika pada umumnya absensi menjadi standar dalam melakukan penilaian, namun kepemimpinan, komitmen, kerjasama, disiplin, orientasi pelayanan, integritas dan kemampuan mengerjakan tugas yang diberikan juga perlu dijadikan indikator untuk melakukan penilaian kinerja pegawai. Tujuan penilaian kinerja pegawai bertujuan untuk memotivasi pegawai agar bersemangat dalam melakukan setiap aktivitas dan untuk pengaruh positif terhadap kerjanya dalam menghadapi tantangan di era globalisasi sekarang. Sistem Pendukung Keputusan sangat diperlukan dalam penilaian kinerja pegawai. Penelitian ini menggunakan sebuah metode Multi Attribut Utility Theory adalah suatu metode perbandingan kuantitatif yang biasanya mengkombinasikan pengukuran atas biaya resiko dan keuntungan yang berbeda. Data yang diolah untuk penilaian kinerja pegawai dalam penelitian ini sebanyak 20 sampel yang bersumber dari Dinas Kependudukan dan Pencatatan Sipil Kabupaten Pesisir Selatan. Penilaian ini didasarkan terhadap beberapa kriteria dan bobot yang ditentukan. Ada 6 data kriteria yang dijadikan dalam penilaian kinerja pegawai. Seperti orientasi pelayanan, integritas, komitmen, disiplin, kerjasama dan sasaran kinerja pegawai. Hasil dari penilaian kinerja pegawai dengan metode Multi Attribute Utility Theory adalah dapat mendukung keputusan penilaian kinerja pegawai menggunakan kriteria-kriteria yang telah ditentukan. Sehingga didapat nilai tertinggi ada pada alternative ke 6 dengan nilai 0.7918 dan nilai yang terendah pada alternatif ke 16 dengan nilai 0.0435 . Nanti akan menjadi bahan pertimbangan bagi Dinas Kependudukan dan Pencatatan Sipil Kabupaten Pesisir Selatan untuk menilai pegawainya dalam periode tertentu. Penilaian kinerja pegawai terbukti dapat membantu Dinas Kependudukan dan Pencatatan Sipil Pesisir Selatan.
\end{abstract}

Kata kunci: Sistem Keputusan, Multi Attribute Utility Theory, Penilaian, Kinerja, Pegawai.

\section{Pendahuluan}

Perkembangan teknologi informasi saat ini sangat berkembang dengan cepat. Pemanfaatan yang sangat luas dalam berbagai bidang kehidupan [1]. Dengan adanya teknologi informasi banyak memberikan kemudahan dalam segala aktifitas. Salah satunya dalam Sistem Pendukung Keputusan (SPK) atau Decision penilaian kinerja pegawai [2]. Pada suatu instansi, Support System (DS) adalah sistem yang menghasilkan dibutuhkan pegawai yang mampu melaksanakan alternatif kriteria untuk memecahkan suatu masalah dan pekerjaan sesuai dengan tujuan dalam mencapai suatu dapat membantu dalam pengambilan keputusan serta target yang menjadi penilaian oleh pimpinan terhadap alat bantu untuk memuaskan semua pihak. Di mana pegawai. Jika pada umumnya absensi menjadi standar dalam melakukan penilaian, namun kepemimpinan, komitmen, kerjasama, disiplin, orientasi pelayanan, integritas [3] dan kemampuan mengerjakan tugas yang diberikan juga perlu dijadikan indikator untuk melakukan penilaian kinerja pegawai [4] 
SPK telah banyak diterapkan dalam menyelesaikan Pertanian dan Perikanan Kota Pontianak. Pengujian pengambilan keputusan suatu masalah [5].

Multi Attribute Utility Theory (MAUT) merupakan suatu metode perbandingan kuantitatif yang biasanya mengkombinasikan pengukuran atas biaya resiko dan keuntungan yang berbeda. Setiap kriteria yang ada memiliki beberapa alternatif yang mampu memberikan Pada penelitian sebelumnya dalam menentukan solusi [6]. Untuk mencari alternatif yang mendekati penerima kredit dengan menggunakan metode Multi dengan keinginan user maka untuk Attribute Utility Theory. Dengan menggunakan data mengidentifikasikannya dilakukan perkalian terhadap PT. XYZ dalam penilaian penentuan penerima kredit, skala prioritas yang sudah ditentukan. Sehingga hasil sehingga dapat meminimalisir adanya resiko kredit yang terbaik dan paling mendekati dari alternatif- macet pada perusahaan [12]. Adapun penelitian alternatif tersebut yang akan diambil sebagai solusi [7].

Untuk mendapatkan alternatif terbaik penilaian kinerja pegawai diawali dengan menentukan normalisasi matrik . Berfungsi mempengaruhi penilaian kinerja dan hasil perhitungan metode Multi Attribute Utility Theory dengan mengalikan bobot setiap kriteria yang sudah ditentukan. Tujuan hasil tersebut untuk pengambilan keputusan [8]. Ada beberapa peneliti sebelumnya yang telah melakukan penelitian penilaian kinerja dengan metode MAUT. Pada penelitian sebelumnya yang melakukan penelitian tentang penentuan karyawan berprestasi dengan menggunakan metode MAUT. Dimana pada penelitian ini bertujuan untuk membandingkan hasil perhitungan antara metode Simple Adaptive Weighting (SAW) dengan Metode Multi Attribute Utility Theory (MAUT). Study kasusnya menggunakan data pada PT. Pertamina RU II Dumai, dengan jumlah sampel sebanyak 10 karyawan. Dari hasil perhitungan didapatkan bawah 5 alternatif dengan nilai terbesar memiliki kemiripan dengan metode SAW, sehingga metode MAUT dapat dijadikan sebagai metode alternatif untuk melakukan perhitungan penentuan karyawan berprestasi [9].

Kemudian penelitian lain sebelumnya yang melakukan penelitian tentang perancangan sistem pendukung keputusan penilaian kinerja karyawan dengan metode MAUT. Dimana data yang digunakan pada PT. Trimulia Gayatri Jambi. Hasil output yang dapat menampilkan data karyawan, data admin, data kriteria, data sub kriteria, data penilaian karyawan dan hasil perhitungan pemberian bonus karyawan. Dari hasil penelitian dengan adanya sistem pendukung keputusan ini untuk pemberian bonus karyawan pada PT. Trimulia Gayatri Jambi sangat membantu perusahaan dalam menentukan karyawan yang berhak mendapatkan bonus dengan hasil yang didapat dan juga memudahkan dalam pengolahan data yang diperlukan [10].

Pada penelitian sebelumnya yang melakukan penelitian tentang pemilihan staf berprestasi dengan metode MAUT . Metode ini dugunakan untuk menentukan nilai bobot dari setiap kriteria, yang kemudian dilakukan proses pengurutan skor akhir dari tertinggi ke terendah (perangkingan) untuk menentukan rekomendasi alternatif terbaik hingga alternatif terburuk. Dimana penelitian ini menggunakan data Dinas Pangan sebelumnya proses seleksi calon penerima bantuan menggunakan metode MAUT, dengan menggunakan 3 kriteria serta 100 sampel dan didapatkan hasil akurasi sebesar $80 \%$. Dimana datanya didapat di Dinas Sosial dan Dinas Disdukcapil [13]. Selanjutnya penelitian tentang penerapan metode MAUT dalam pemilihan rumah kost menyimpulkan metode MAUT mampu memberi saran atau rekomendasi dalam pemilihan rumah kost secara objektif. Dimana datanya menggunakan RT terdekat [14].

Pada penelitian dengan SPK pemberian pinjaman modal usaha ini dengan metode maut, dapat dengan mudah melakukan pendataan calon kandidat yang akan diberikan pinjaman modal usaha dan serta menghasilkan output berupa laporan yang dapat dilakukan dengan cepat, tepat dan akurat [15]. Pada penelitian yang telah dilakukan dengan pemilihan tenaga kesehatan teladan antara lain, telah dihasilkan SPK yang mampu memberikan rekomendasi pemilihan tenaga kesehatan teladan. Penerapan metode maut memberikan hasil akurasi sebesar $86,67 \%$, dari hasil tersebut menunjukkan bahwa metode maut bisa menjadi metode alternatif [16]. Pada pengujian sistem dalam pemetaan tingkat dampa bencana banjir di kabupaten bantul dengan validasi sistem dapat diambil kesimpulan hasil pemetaan tingkat dampak yang dihasilkan dari sistem memiliki tingkat keakuratan $95 \%$ jika dibandingkan dengan hasil pemetaan yang dilakukan oleh BPBD Kabupaten Bantul dikarenakan data kriteria yang digunakan pada sistem tidak sama. Sehingga jika terjadi penambahan kriteria pada sistem ada kemungkinan akan terjadi perubahan pada hasil pemetaan atau hasil nilai perhitungannya [17].

Pada metode MAUT hasil akhirnya mendapatkan perengkingan nilai dari yang tertinggi sampai yang terendah. Dinas Kependudukan dan Pencatatan Sipil membutuhkan Sistem Pendukung Keputusan menggunakan metode MAUT untuk mempermudah penilaian kinerja pegawai dengan tepat.

\section{Metodologi Penelitian}

Metode penelitian merupakan rancangan dari kegiatan penelitian yang dilakukan dalam mencari, merumuskan serta menganalisa hingga dapat menyusun sesuatu dengan langkah-langkah yang akan digunakan dan waktu yang dapat digunakan sebagai acuan dalam 
memperoleh dalam analisa data. Metode penelitian 2.3 Mempelajari Literatur diperlukan guna untuk membantu penulisan dapat terarah sesuai dengan masalah yang diteliti.

Mempelajari literatur juga sangat penting dilakukan agar mempunyai landasan baik secara teoritis yang Penelitian adalah cara yang sistematis untuk menjawab benar dan dijelaskan oleh para peneliti dan ahli suatu masalah yang akan di teliti dan dari kata sebelumnya. Mempelajari literatur maka penelitian sistematis ini sendiri ada kaitannya dengan metode yang dilakukan tidak mengada-ada sehingga penelitian ilmiah yang berarti ada keterkaitan prosedur yang tersebut nantinya dapat diterima di dunia ilmu ditandai dengan adanya ketuntasan dan keteraturan. pengetahuan dan masyarakat umum.

Metode sangat diperlukan dalam membuat penulisan supaya dapat terarah dengan baik.

Metode tersebut bersifat objektif, artinya objektivitas tersebut mampu menghasilkan penelitian yang dapat dijadikan sebagai acuan oleh peneliti lainnya. Metode tersebut memiliki sifat yang kritis, serta secara analisis mampu menunjukan proses yang tepat dan benar dalam mendefenisikan masalah dengan suatu metode. Metode yang digunakan juga memiliki sifat yang logis, berarti mampu memberikan argumen yang baik. Pada bagian ini penulis melaksanakan studi literatur termasuk 2.5 Menganalisa Data Menggunakan Metode Multi dengan membaca dan mengumpulkan berbagai bahan Attribute Utility Theory

dari buku-buku, jurnal-jurnal komputer yang membahas masalah yang berkaitan dengan penelitian ini serta sumber lainnya.

Kerangka kerja penelitian adalah suatu alur sistematis yang digunakan dalam penelitian. Berikut ini kerangka kerja penelitian yang disajikan pada Gambar 1 .

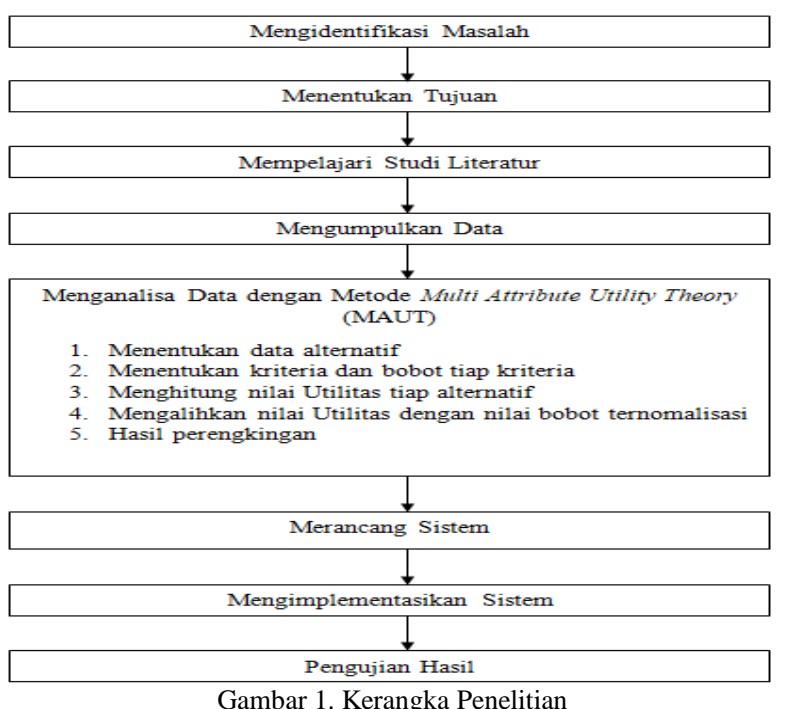

\subsection{Mengidentifikasi Masalah}

Tahapan identifikasi masalah merupakan langkah awal dalam penelitian ini. Tahapan ini penting karena peneliti melakukan perumusan masalah dari masalah yang ditemukan pada objek penelitian serta memberikan batasan dari permasalahan yang diteliti agar lebih terarah.

\subsection{Menentukan Tujuan}

Menentukan tujuan penelitian diperlukan agar peneliti tidak menyimpang dari tujuan yang ingin dicapai untuk mendapatkan hasil optimal. Tahap ini memperjelas ruang lingkup dan batasan masalah.

Agar permasalahan penelitian ini dapat di analisa maka digunakan metode MAUT.

\subsection{Merancang Sistem}

Tahapan merancang sistem dilakukan setelah proses analisa data. Tahapan ini dilakukan proses perancangan sistem yang terdiri dari struktur data, program, format masukan (input), dan format keluaran (output). Merancang sistem merupakan rancangan awal sebelum sistem itu digunakan.

\subsection{Mengimplementasikan Sistem}

Sistem yang dirancang menggunakan bahasa pemrograman PHP yang menerapkan metode MAUT. Mengimplementasikan sistem merupakan tahap uji coba sehingga siap untuk dioperasikan.

\subsection{Pengujian Hasil}

Merupakan tahapan yang terakhir dari penelitian, yaitu dilakukan pengujian untuk membandingkan hasil dari sistem aplikasi yang dirancang dengan hasil perhitungan manual dengan metode MAUT. Tujuan tahap ini mengetahui apakah diperoleh kesamaan antara hasil output dari analisis aplikasi dengan perhitungan manual.

\section{Hasil Pembahasan}

\subsection{Data}

Penelitian ini menggunakan data Dinas Kependudukan dan Pencatatan Sipil Kabupaten Pesisir Selatan. Dalam pengumpulan data ini dilakukan pengambilan langsung kelapangan dan wawancara dengan Kepala Disdukcapil Kabupaten Pesisir Selatan di Painan. Data tersebut berupa data pegawai pns dan data nilai berdasarkan kriteria yang akan digunakan nantinya dalam melakukan SPK dengan metode MAUT. 


\subsection{Analisa Sistem}

Berdasarkan algoritma proses MAUT diatas maka digambarkan melalui pseudocode yang disajikan pada Algoritma 1.

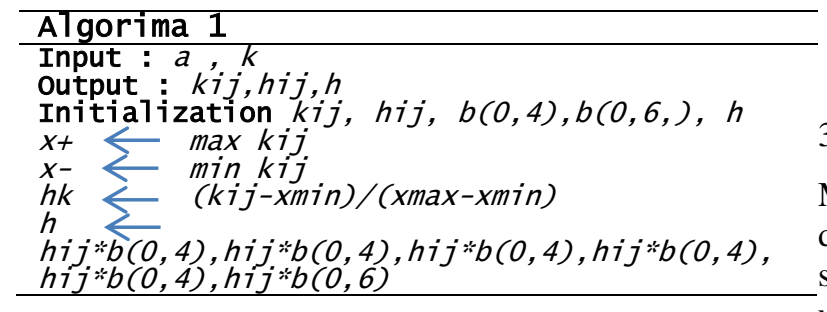

Pseudocode diatas nantinya akan diterapkan kedalam bentuk sistem yang akan dibangun menggunakan Bahasa pemrograman PHP menggunakan bantuan database MySQL sebagai tempat penyimpanan data.

\subsection{Menentukan Data Pegawai} Pada penelitian ini digunakan 20 sampel data pegawai i disemua alternatif, xi- merupakan nilai terkecil dari dari Dinas Kependudukan dan Pencatatan Sipil kriteria ke i disemua alternatif dan xi+ merupakan nilai Kabupaten Pesisir Selatan.

\subsection{Menentukan Data Alternatif}

Dalam pengambilan keputusan dengan metode MAUT terdapat pemberian kode alternatif yang dibutuhkan dalam melakukan seleksi terhadap pengambilan keputusan penilaian pegawai. Kode alternatif yang disajikan pada Tabel 1.

Tabel 1. Pemberian Kode Alternatif

\begin{tabular}{cccccccc}
\hline KD & NM & K1 & K2 & K3 & K4 & K5 & K6 \\
\hline S1 & YB & 92 & 82 & 81 & 82 & 82 & 83 \\
S2 & DM & 90 & 91 & 82 & 91 & 83 & 83 \\
S3 & WD & 85 & 88 & 91 & 87 & 85 & 91 \\
S4 & WT & 82 & 82 & 80 & 95 & 85 & 84 \\
S5 & DS & 91 & 82 & 81 & 80 & 81 & 91 \\
S6 & INS & 95 & 91 & 91 & 93 & 94 & 111 \\
S7 & YO & 91 & 92 & 90 & 91 & 86 & 88 \\
S8 & HP & 82 & 81 & 82 & 82 & 82 & 84 \\
S9 & SY & 91 & 91 & 92 & 92 & 111 & 94 \\
S10 & ZL & 85 & 91 & 90 & 111 & 84 & 85 \\
S11 & KS & 86 & 95 & 95 & 84 & 90 & 91 \\
S12 & SY & 90 & 91 & 92 & 91 & 89 & 94 \\
S13 & JM & 92 & 80 & 91 & 88 & 80 & 89 \\
S14 & IG & 111 & 92 & 90 & 94 & 93 & 91 \\
S15 & IS & 80 & 91 & 81 & 81 & 81 & 91 \\
S16 & RY & 83 & 83 & 82 & 84 & 83 & 83 \\
S17 & JR & 92 & 92 & 93 & 90 & 92 & 90 \\
S18 & ZH & 97 & 96 & 96 & 97 & 98 & 90 \\
S19 & FDY & 89 & 89 & 91 & 92 & 94 & 89 \\
S20 & PA & 89 & 111 & 94 & 93 & 92 & 91 \\
\hline
\end{tabular}

3.5 Menentukan Kriteria, Bobot Tiap Kriteria dan Sub Bobot Tiap Kriteria

Dalam pengambilan keputusan dengan metode MAUT terdapat kriteria dan bobot yang dibutuhkan dalam melakukan seleksi terhadap pengambilan keputusan penialaian kinerja pegawai yang disajikan pada Tabel 2 .
Tabel 2. Kriteria dan Bobot Tiap Kriteria

\begin{tabular}{clc}
\hline No & \multicolumn{1}{c}{ Nama Kriteria } & Bobot \\
\hline 1 & Orientasi Pelayanan & 0,08 \\
2 & Integritas & 0,08 \\
3 & Komitmen & 0,08 \\
4 & Disiplin & 0,08 \\
5 & Kerjasama & 0,08 \\
6 & Sasaran Kinerja Pegawai & 0,6 \\
\hline
\end{tabular}

\subsection{Menghitung Nilai Utilitas Tiap Alternatif}

Metode Multi Attribute Utility Theory mengubah nilai data yang ada pada kriteria dengan menjadi skala 0 sampai 1, 0. Nilai hasil utility terbawah dan 1 nilai hasil utility tertinggi dengan persamaan yang disajikan pada Persamaan (1).

$U(x)=\frac{x-x i-}{x i+-x i}$

terbesar dari kriteria ke i disemua alternatif. Hasil perhitungan disajikan pada Tabel 3.

Tabel 3. Hasil Matriks Normalisasi

\begin{tabular}{lllllll}
\hline Kode & K1 & K2 & K3 & K4 & K5 & K6 \\
\hline S1 & 0,38 & 0,06 & 0,06 & 0,06 & 0,06 & 0 \\
S2 & 0,32 & 0,35 & 0,12 & 0,35 & 0,09 & 0 \\
S3 & 0,16 & 0,25 & 0,68 & 0,22 & 0,16 & 0,28 \\
S4 & 0,06 & 0,06 & 0 & 0,48 & 0,16 & 0,03 \\
S5 & 0,35 & 0,06 & 0,06 & 0 & 0,03 & 0,28 \\
S6 & 0,48 & 0,35 & 0,68 & 0,41 & 0,45 & 1 \\
S7 & 0,35 & 0,38 & 0,62 & 0,35 & 0,19 & 0,19 \\
S8 & 0,06 & 0,03 & 0,12 & 0,06 & 0,06 & 0,03 \\
S9 & 0,35 & 0,35 & 0,75 & 0,38 & 1 & 0,39 \\
S10 & 0,16 & 0,35 & 0,62 & 1 & 0,12 & 0,07 \\
S11 & 0,19 & 0,48 & 0,93 & 0,12 & 0,32 & 0,28 \\
S12 & 0,32 & 0,35 & 0,75 & 0,35 & 0,29 & 0,39 \\
S13 & 0,38 & 0 & 0,68 & 0,25 & 0 & 0,21 \\
S14 & 1 & 0,38 & 0,62 & 0,45 & 0,41 & 0,28 \\
S15 & 0 & 0,35 & 0,06 & 0,03 & 0,03 & 0,28 \\
S16 & 0,09 & 0,09 & 0,12 & 0,12 & 0,09 & 0 \\
S17 & 0,38 & 0,38 & 0,81 & 0,32 & 0,38 & 0,25 \\
S18 & 0,54 & 0,51 & 1 & 0,54 & 0,58 & 0,25 \\
S19 & 0,29 & 0,29 & 0,68 & 0,38 & 0,45 & 0,21 \\
S20 & 0,29 & 1 & 0,87 & 0,41 & 0,38 & 0,28 \\
\hline
\end{tabular}

3.7 Mengalihkan Nilai Utilitas dengan Nilai Bobot Ternomalisasi

Nilai setiap kriteria dilakukan proses perhitungan perkalian normalisasi untuk menentukan hasil akhir yang memiliki persamaan sebagai berikut :

$\mathrm{v}(\mathrm{x})=\sum \mathrm{n} \mathrm{i}=1$ wi vi(x)

Dimana $v(x)$ merupakan evaluasi total alternatif ke-x, wi merupakan bobot relative kriteria ke-i, vi(x) merupakan hasil evaluasi atribut (kriteria) ke-i untuk alternatif ke-x, i merupakan indeks untuk menunjukkan kriteria dan $n$ merupakan jumlah kriteria. Hasil perhitungan matriks dari perangkingan dapat dilihat pada Tabel 4. 
Tabel 4. Hasil Perhitungan Perangkingan

\begin{tabular}{lccc}
\hline No & Kode Alternatif & Hasil & R \\
\hline 1 & S1 & 0.0515 & \\
2 & S2 & 0.1003 & \\
3 & S3 & 0.2909 & \\
4 & S4 & 0.0834 & \\
5 & S5 & 0.2126 & \\
6 & S6 & 0.7918 & \\
7 & S7 & 0.2604 & \\
8 & S8 & 0.0495 & \\
9 & S9 & 0.4635 & \\
10 & S10 & 0.2245 & \\
11 & S11 & 0.3368 & \\
12 & S12 & 0.4015 & \\
13 & S13 & 0.2352 & \\
14 & S14 & 0.4021 & \\
15 & S15 & 0.2100 & \\
16 & S16 & 0.0435 & \\
17 & S17 & 0.3337 & \\
18 & S18 & 0.4055 & \\
19 & S19 & 0.2971 & \\
20 & S20 & 0.4092 & \\
\hline
\end{tabular}

Setelah perhitungan didapatkan dilakukan keputusan dari rangking tertinggi sampai rangking terendah, sehingga hasil disajikan pada Tabel 5.

Tabel 5. Tabel Keputusan

\begin{tabular}{lccc}
\hline No & Kode Alternatif & Hasil & Rangking \\
\hline 1 & S6 & 0.7918 & 1 \\
2 & S9 & 0.4635 & 2 \\
3 & S20 & 0.4092 & 3 \\
4 & S18 & 0.4055 & 4 \\
5 & S14 & 0.4021 & 5 \\
6 & S12 & 0.4015 & 6 \\
7 & S11 & 0.3368 & 7 \\
8 & S17 & 0.3337 & 8 \\
9 & S19 & 0.2971 & 9 \\
10 & S3 & 0.2909 & 10 \\
11 & S7 & 0.2604 & 11 \\
12 & S13 & 0.2352 & 12 \\
13 & S10 & 0.2245 & 13 \\
14 & S5 & 0.2126 & 14 \\
15 & S15 & 0.2100 & 15 \\
16 & S2 & 0.1003 & 16 \\
17 & S4 & 0.0834 & 17 \\
18 & S1 & 0.0515 & 18 \\
19 & S8 & 0.0495 & 19 \\
20 & S16 & 0.0435 & 20 \\
\hline
\end{tabular}

Hasil perangkingan pada tabel 5 didapatkan nilai tertinggi adalah pada alternatif ke 6 yaitu S6 dengan nilai 0,7918. Sedangkan nilai terendah adalah pada alternatif ke 16 yaitu S16 dengan nilai 0,0435. Setelah [ hasil perangkingan diperoleh dilakukan proses pengambilan keputusan berdasarkan 20 sampel ditetapkan oleh Kepala Dinas Kependudukan dan Pencatatan Sipil Kabupaten Pesisir Selatan.

\section{Kesimpulan}

Dengan adanya metode MAUT dapat digunakan dalam melakukan penialain kinerja pegawai berdasarkan kriteria-kriteria yang ditentukan. Beberapa kriteria yang digunakan adalah orientasi pelayanan, integritas, komitmen, disiplin, kerjasama dan sasaran kinerja pegawai. Hasil nilai yang didapatkan bahwa nilai tertinggi terdapat pada alternatif ke 6 dengan nilai 0,7918 dan nilai terendah terdapat pada alternatif ke 16 dengan nilai 0,0435. Penelitian ini dapat membantu pihak Dinas Kependudukan dan Pencatatan Sipil Kabupaten Pesisir Selatan dalam melakukan penilaian kinerja pegawai.

\section{Daftar Rujukan}

[1] Listiani, I. (2021, May 29). Analisis Pentingnya Sistem Informasi Manajemen Dalam Teknologi Informasi dan Komunikasi saat ini. http://Doi.Org/10.31219/Osf.Io/6qmj4

[2] Asman, M., \& Darmalia, N. (2021). Pengaruh Penerapan Absensi Sidik Jari (Fingerprint) dan Disiplin Kerja Pegawai Negeri Sipil Dalam Meningkatkan Kinerja Pegawai Pada Badan Pengelola Keuangan dan Aset Daerah Kabupaten Bungo. Jurnal Manajemen Sains, 1(1). http://Doi:10.36355/Jms.V1i1.476

[3] Hendi, H., Irawati, I., \& Candradewini, C. (2019). Perencanaan Kinerja: Suatu Studi Tentang Pengaruh Sasaran Kerja Pegawai Negeri Sipil (Skp) Terhadap Kinerja Pegawai Pada Badan Daerah Di Kabupaten Merangin. Jurnal Manajemen Pelayanan Publik, 2(2), 87. http://Doi:10.24198/Jmpp.V2i2.20608

Wasitowati, W., \& Khoiriyah, B. (2019). Pengaruh Kepemimpinan Konsiderasi, Disiplin Kerja Dan Orientasi Kerja Terhadap Kinerja Pegawai Melalui Motivasi Berprestasi (Studi Kasus Pada Pns Kecamatan Di Kabupaten Grobogan). Solusi, 16(4). http://Doi:10.26623/Slsi.V16i4.1666

[5] Budiman. (2019). Sistem Pendukung Keputusan Penilaian Mahasiswa Berprestasi Berbasis Web (Studi Kasus: Amik Hass). http://Doi:10.31227/Osf.Io/Px84j

[6] E. Satria, N. Atina, M. E. Simbolon, and A. P. Windarto. Spk: Algoritma Multi-Attribute Utility Theory (Maut) Pada Destinasi Tujuan Wisata Lokal Di Kota Sidamanik. Comput. Eng. Sci. Syst. J., vol. 3, no. 2, p. 168, 2018 http://doi.org/10.24114/cess.v3i2.9954

[7] Yolanda Agustina Sitmorang, Nurhafidah Dalimunthe, Lin Parlina, Muhammad Ridwan Lubis. Penerapan Metode Maut Pada Pemilihan Bimbingan Intensif Terbaik Di Pematangsiantar. KOMIK (Konferensi Nasional Teknologi Informasi dan Komputer) Volume 2, Nomor 1, Oktober 2018. http://doi.org/10.30865/komik.v2i1.934

[8] Selvia Djasmayena, Yuhandri Yunus, Rezi Elsya Putra. Pemilihan Supplier Obat yang Tepat Menggunakan Metode Multi Attribute Utility Theory. Jurnal Informasi \& Teknologi $\begin{array}{llll}\text { Vol. } & 1 & \text { No.4, } & \text { Desember }\end{array}$ http://doi.org/10.37034/jidt.v1i4.23

[9] LM. Fajar Israwan, Muh. Mukmin, Sandi Ardiansyah. Penentuan Karyawan Berprestasi Menggunakan Metode Multi Attribute Utility Theory (MAUT). Jurnal Informatika, Vol.9 No.1 Juni 2018 ISSN Online: 2528-0090. http://doi.org/10.15575/join.v1i2.46

0] Gustin Yoslando, Abdul Rahim, Amroni. (2019). Perancangan Sistem Pendukung Keputusan Penilaian Kinerja Karyawan (Studi Kasus : PT. Trimulia Gayatri Jambi). Jurnal Ilmiah Mahasiswa Teknik Informatika, Vol 1, No.4. http://doi.org/10.14210/vd.v19n01.p76-86

[11] Kariman Ridho, Heri Priyanto, and Helen Sastypratiwi. (2020). Implementasi Metode Multi Attribute Utility Theory (MAUT) Pada Aplikasi Pemilihan Staf Berprestasi Dinas Pangan Pertanian Dan Perikanan Kota Pontianak. Jurnal Sistem dan Teknologi Informasi, vol. 8, No. 2. http://dx.doi.org/10.26418/justin.v8i2.38234

12] Novri Hadinata. (2018). Implementasi Metode Multi Attribute Utility Theory (MAUT) Pada Sistem Pendukung Keputusan dalam Menentukan Penerima Kredit. Jurnal SISFOKOM, Volume $\quad 07$, Nomor http://doi.org/10.32736/sisfokom.v7i2.562 
[13] Derry Fajirwan, Muhammad Arhami, Ismi Amalia. (2018). [16] Ramadiani, Auliana Rahmah. (2019). Sistem Pendukung Sistem Pendukung Keputusan Penerimaan Bantuan Renovasi Rumah Dhuafa Menggunakan Metode Multi Attribute Utility Theory. Jurnal Infomedia Vol. 3 No.. http://doi.org/10.30811/jim.v3i2.713 Keputusan Pemilihan Tenaga Kesehatan Telatan menggunakan Metode Multi Attribute Utility Theory. Jurnal Ilmiah Teknologi $\begin{array}{llll}\text { Sistem Informasi } & \text { Vol. } & 5, & \text { No.1. }\end{array}$ http://doi.org/10.26594/register.v5i1.1273

[14] R. N. Sari and R. S. Hayati. (2019). Penerapan Metode Multi [17] Afif Irfan Abdurrahman, Bambang Yuwono, Yuli Fauziah. Attribute Utility Theory (MAUT) Dalam Pemilihan Rumah Kost. J-SAKTI Jurnal Sains Komput. dan Inform., vol. 3, no. 2, p. 243. http://doi.org/10.30645/j-sakti.v3i2.144

[15] Asyahri Hadi Nasyuha. (2019). Sistem Pendukung Keputusan Menentukan Pemberian Pinjaman Modal dengan Metode Multi Attribute Utility Theory. Jurnal Media Informatika Budidarma, Vol 3, No 2.http://doi.org/10.30865/mib.v3i2.1093 (2020). Penerapan Metode Multi Attribute Utility Theory (MAUT) Dalam Pemetaan Tingkat Dampak Bencana Banjir di Kabupaten Bantul. Jurnal Telematika Vol.17, No.1. http://doi.org/10.31315/telematika.v17i1.3402 